\title{
COUNSELOR DEVELOPMENT AS THE HERO'S JOURNEY: REFLECTIONS FROM A COUNSELOR EDUCATOR
}

\author{
Daniel A. Kaufmann, Grand Canyon University
}

\begin{abstract}
The use of the monomyth to shape the narratives of fiction with deep meanings, while feeling both new and recognizable, is consistently experienced across all cultures throughout time. As past publications have utilized this approach to subconscious symbolism to explain many experiences, it has not yet been utilized to explain the process of counselor development. The structures utilized in this exploration of the Hero's Journey concept include the seminal work Hero with a Thousand Faces by Joseph Campbell (1949) being applied to the structure of counseling development as reviewed by Rønnestad and Skovholt (2003). Each stage of the journey will be translated into an understanding of how students grow from before their master's program through their senior years as experts in the counseling field. The following article will engage this metaphor to explore the narrative of a counseling student on their quest to become a counseling professional through use of the stages from the monomyth as used to describe the Hero's Journey.

Keywords: monomyth, hero's journey, archetypes, counselor development \section{INTRODUCTION}

Counseling students are exposed to countless opportunities to wrestle with their own journey of personal growth (Rønnestad \& Skovholt, 2003), starting with the moment they begin their counseling program and continuing through their decision to walk away from their active role as a senior professional in the mental health field. Counselor development in relation to academic achievement expands far beyond the concept of merely passing classes and acquiring knowledge. Although writing papers and passing exams are traditional elements of the graduate school challenge, these are secondary in counseling programs next to the importance of acquiring other abilities and traits (McBride Steinberg, 2014). Such transformations affect the person's moral and ethical qualities, their understanding of microskills, their ability to apply the concepts of theory and intervention to situations involving real people, and the awareness

they use to keenly develop social connection with clients who are receiving clinical services. As this journey requires a greater component of struggle than the simple academic task of achieving grades, it is possible to analyze the necessity of this growth through the lens of the Hero's Journey, as established in the works of Joseph Campbell.

In The Hero with a Thousand Faces, Campbell (1949) explores the archetypal themes of hero stories across centuries of storytelling to identify our connection with the meaning we find in our world. From an historical context, psychoanalysis and other early works of psychology have been used as the core to this approach by analyzing the deeper meaning of subconscious imagery. Campbell utilized insight from the works of Carl Jung and Sigmund Freud to take advantage of the fascination people maintained during that time period to achieve greater understanding of the human mind (Byrne, 2000). In Campbell's own
\end{abstract}


words, "Mythology ... is psychology misread as biography, history, and cosmology" (1949, p. 256). The hero of the monomyth comes from nothing and is tasked with embarking on a quest to overcome insurmountable challenges. With guidance, luck, and favor granted by the prevailing forces within the universe, the hero is able to traverse these difficulties to fulfill their destiny and master the world of the adventure. In doing so, the hero becomes a symbol of triumphant hope that is capable of harnessing the power of the World Navel ((the mythological source of being for the universe) to save the people of the ordinary world from certain oblivion. The decision of whether to start the journey can even be said to mimic the decision faced by a future graduate student when reflecting on the turmoil of the world and deciding whether they have the potential as a counselor to help the residents of their community overcome it. If they select this task for themselves, they can assist with restoring hope through becoming a trained helper to the counseling services in the community. For the hero, there are many defined stages that go beyond the "crossing of the threshold" or the "refusal of the call," with our literature ultimately resolving the story through the triumph of the hero returning with the boon but being forever changed by the journey (Campbell, 1949; Jones, 2014). So too does the counseling student complete their program, become licensed, cultivate their clinical skills, and acquire the gift of hope to lend to others, but also they possess a new awareness of how the pain in the world truly seems to exist in perpetuity.

Incoming counseling students often cite the desire to help others through their lifelong struggles as a primary motivation for pursuing the role of the professional counselor (Rønnestad \& Skovholt, 2003). For them, this is the initial quest they must decide either to accept or reject. The acceptance of this challenge can, in itself, be viewed as a form of heroism (Lawson, 2005), and this decision is often propelled by a desire to help others in the new counseling student. This drive could be to assist specific populations or problem areas the students have identified as being specifically of concern as they collected their observations of the ordinary world. Crossing this threshold will lead to many experiences they have yet to face, from learning from their mentors (instructors, supervisors, and experienced representatives of the field), to struggling with their shadow self (ethics and moral development) (Ladkin, Spitler, \& Craze, 2018; Stein, 1998) and becoming their own self, free of the mentor's guidance in a field larger than they had realized (state licensure), and then moving toward the later stages of their professional development while armed with all the abilities of this acquired experience.

To this point, published works exploring the Hero's Journey as a counseling concept have focused on application as a clinical intervention with clients (Pieracci, 1990), research and inquiry for students (Holmes, 2007), or uses related to service delivery for other healthcare professions (Dybicz, 2012; Fortune et al., 2016). The following discussion will connect the phases of experience the hero encounters within the monomyth directly to the identified stages and themes of counselor development. This perspective is drawn from the firsthand observations of a counselor educator reflecting on their lived experience from the master's and doctoral journey and synthesizing these memories with relevant experiences from delivering counseling principles to students in traditional and online classrooms.

\section{DEPARTURE: STARTING THE JOURNEY OF COUNSELOR DEVELOPMENT}

\section{The Call to Adventure for the Beginning Student}

Prior to enrolling in a graduate-level counseling program, incoming students are often already interested in helping others in a way that leads to a feeling of personal satisfaction or necessity (Rønnestad \& Skovholt, 2003). As a lay helper, the personal drive of the individual to identify problems and guide those affected by the situation towards solutions is often well-intentioned. This often leads to conflict over time, as the person realizes they cannot be the helper they strive to be while being limited to helping only those within their social reach and they lack the credibility of a trained helper of others. As the person looks out from this circle, the ordinary world can feel overwhelming as it reminds the well-intentioned prospective student that the problem, if not insurmountable, is bigger than them. This ordinary world is society as a whole. The question of what to pursue is highlighted for the person through the herald of change, which is the inciting event that 
pushes the potential student to choose one way or the other. This could be a family event, a personal trauma, the supportive insight from friends and family, or many other situations. The herald is whatever happenings present the person with the choice to embark on the journey or refuse and continue enjoying the ordinary world. Through this occurrence, the person is faced with the decision of whether to apply to graduate programs in counseling and embark on a three-year journey of personal transformation as a graduate student or continue to face the ordinary world knowing they lack the power to guide the world they know towards meaningful change.

\section{Overcoming a Refusal of the Call}

Should the potential student elect not to pursue their role as a hero through counseling, this is when the hero experiences the "refusal of the call" (Campbell, 1949). Fictional tales often depict the character who will become the hero being presented with the problem unexpectedly and initially choosing not to let this desperate prompt become their problem. Bilbo informs Gandalf that Baggins's belong in the Shire (Tolkien, 1937), while Luke Skywalker laments to Obi-wan Kenobi that the planet Alderaan is "such a long way from here" (Kurtz, 1977). To them, the ordinary world already feels big enough to be the entire world, and the universal threat to autonomy and wellness still feels far enough away that the protagonist can pass the worry back to the mentor who is seeking their companionship.

For future or could-be counselors, the master's program would be too taxing for life at the present time, indicated by them thinking "I can't complete that level of schooling." The person doubts that they would even be compatible with the counselor role if it were a professional job, and so lay helping is, in this moment, the ceiling for their potential. Ironically, this is similar to a person needing the help of counseling but deciding now is not the time to further tax their busy life with this kind of service (Lawson, 2005), and they continue on without the help of their own counseling mentor. In order to provide greater help to others, this decision must be made in the affirmative, which allows the journey to begin.

In order to return to the trajectory of the counselor as a hero, the above examples must experience a shift in desire, and the could-be counselor, as an informal helper, begins to see value in formally becoming a helper of others (Egan, 2014). Rather than avoid the challenge, the herald of change convinces the prospective student to apply for counseling programs and find the place where they fit into the daunting task of earning their graduate degree as a counselor. Once the fictional hero observes this compelling signal, they feel assured that the comfort zone of the isolated/ ordinary world will not hold the corruption of the World Navel back (i.e., depression, anxiety, trauma, etc.), so the hero is forced to join the mentor-inneed on a dangerous journey. At this stage, the lay helper believes their potential to help others is more important than the risks of being defeated by their fear, meaning it is now the right time to take the first steps towards becoming a graduate learner in counseling.

\section{Crossing the First Threshold: \\ Facing the Curriculum}

Upon acceptance into the counseling program, the newly admitted student must experience a shift in time management (Hurst, Cleveland-Innes, Hawranik, \& Gauvreau, 2013) to account for the intense time commitment common to the tasks of graduate school. Additionally, the students may be tasked with enduring a workload of reading and counseling activities that challenge the belief system they subscribed to during the lay phases of their previous life (Rønnestad \& Skovholt, 2003). Morality is now intertwined with ethics. Helping guidance is now blended with counseling theory and clinical skills. Problems and solutions are now implications of psychopathology and diagnosis. The ordinary world has been fled, and now the hero (as a graduate student) will cross the threshold to embark on a journey into a new world of the supernatural (or psychological) (Byrne, 2000). These forces are unfamiliar, yet they lend an air of excitement by more convincingly explaining the phenomena of life that the student-hero is excited to personally master. This world will provide a test unlike any other they have encountered, and yet the student will move forward because their goal is making a difference for the world they left behind where help is simple enough to not need the title of professional counselor. The world ahead is one where this very role becomes a cornerstone of the 
student reborn, in possession of refined purpose, and the "supernatural" aid of clinical skills passed down to them by their instructors in the role of the mentor. Crossing this threshold signals the initiation of the journey (Jones, 2014) towards becoming a professional counselor.

\section{Reflection: Meeting the Mentor}

As a counselor educator, I have many goals for students who experience either my traditional classroom learning or my online learning. While each pose unique obstacles and surprising similarities, I always aim to be encouraged by the desire to learn from students who stay engaged and go the extra step to interact with me in a way that mimics the early journey of our heroes from fiction. One key difference between learning to be a counselor versus other professions is the internal connection with living the principles being learned. Counseling does not become merely something a person does, but it actually becomes who a person is. For this reason, I see myself as the mentor on these journeys, the beacon for the supernatural aid that Campbell mentions as an archetype of empowerment to the hero early on in the monomyth. While the talisman that represents this aid is usually depicted as a magic wand (Rowling, 1997) or a ring of power (Tolkien, 1937), my aid lies in the use of theories, scholarship, ethics, cultural competence, and counseling skills. These are the principles the counseling student will be relying on throughout their professional development to challenge the afflictions of depression, anxiety, trauma, psychosis, and the like in the endless quest our field faces to improve the quality of life for those seeking counseling services. While these concepts may not be as visually inspiring as a lightsaber flashing across the screen, in my mind the successful use of these skills as personal qualities will serve my students well in their quest towards being an exceptional helper of people with all forms of psychological struggle.

Before the lay helper even makes it into a classroom, they must complete their first challenge on the academic road of trials: the application process. While each academic institution may approach this differently, I have observed that some students are supremely prepared for the task, having spent an excess of time and focus thinking through the tangible qualities of how a student would want to engage this challenge. Others, however, may not fully understand the enormity of the commitment to the graduate student lifestyle (Hurst et al., 2013) or the degree of devotion to the basic dispositions expected of a student pursuing counseling (Redekop \& Wlazelek, 2012). In many ways, the challenge at these early stages is deciding who is ready to embark on the journey and likely to adhere to the values of the field while fulfilling the requirements of the university. This calls many images to me from across stories of myth and literature, from the sorting hat or receipt of a letter from the owls in Harry Potter (Rowling, 1997) to the selection of who can be trained as a Jedi in the prequel entries of Star Wars (McCollum, 1999). Upon acceptance, the initiation of coursework can be seen in our counseling monomyth as the next test, which corelates strongly with what is referred to in the telling of Jonah in the Old Testament as, quite literally, the "belly of the whale."

From my role as the mentor to master's and doctoral learners, this phase of the journey is the segment of the struggle where I am granted the most personal interaction in shaping the developmental process of the counselor as my student. For many credit hours of tasks, the student is free to see me as the source of the challenge, their adversary, but also their guide, mentor, advisor, and hopefully, in the right moments, cheerleader and source of professional support. I strive to pass the values of theory, core professional philosophy, and clinical skill, all of which hold a heritage in the field, on to my students so they too may use them with clients that demand these actions from them. Unsurprisingly, as I teach theories, I am automatically drawn to discuss the Hero's Journey as a metaphor for the counseling philosophy of each approach, how client change works, and also setting goals for certain approaches. Any time the client is working towards meaningfulness (existential), behavioral success, congruence (person-centered), and any number of other elements of the counseling process (Murdock, 2017), I cannot escape the connections between what it takes to become truly this counselor and the parallels between the path my students are taking with me and later on the paths their clients will take with them (Pieracci, 1990).

In approaching the content of my profession in this way, I hope my students will perceive in me 
a model for what they aim to be as a counseling professional (Jena, 2015). This way, I can become a launching point for learning concepts that the student can then subjectively interpret as they begin utilizing their own ideas from the research they conduct to complete the assignments of my course. The relationship we forge is a huge determinant of which outcome the student will choose to adhere (Trepal, Haberstroh, Duffey, \& Evans, 2007). For this reason, I look to be a model of the field, seeking the source of hope in the future of my craft and offering to guide the new hero into the role at the initiation of their own rebirth into this new role. In the mentor role, I am symbolically matching the archetypes of characters such as Morpheus in The Matrix (Berman, 1999), Gandalf in The Lord of the Rings (Tolkien, 1954), and Obi-wan Kenobi in the original Star Wars trilogy (Kurtz, 1977).

\section{Lessons from the Belly of the Whale}

Throughout the duration of graduate coursework, the student will be expected to meet the requirements of a number of tasks (Rønnestad \& Skovholt, 2003), many of which will tax the intellect and patience of the student. Researchoriented writing, group presentations, and working to effectively encapsulate abstract processes likely to be encountered throughout counseling work become the status-quo for the student in the "belly" of the curriculum. Over time, the student is expected to identify which theories they align with, and as such, they will also have collected a repertoire of counseling skills, theory-oriented techniques or interventions, assessment strategies, case conceptualizations for diagnosing client problems, and many other knowledge-oriented methods they will deliver in face-to-face scenarios with real clients once learning shifts to application (Hurst et al., 2013). Additionally, the student will consistently receive feedback from those training them in the educational tasks as they progress from course to course. As the Hero of the monomyth is entrenched in the belly of the whale, so also would the student face many difficulties in situations where they are displaying problematic student behaviors (Brown, 2013) or not perceiving their progress in skills as a counselor to be satisfactory, by either internal or external measures (Cicco, 2012). However, there is no turning back in most cases of this kind, with the student being invested in their program and the hero's very livelihood resting in the outcome of this very real threat illustrated by the whale of the journey (Campbell, 1949). It is good to develop resilience during this phase of counselor development, as the pressures involved in completing assignments, which feel absolute in the moment, is only a glimpse of the pressures the student will certainly face later in becoming a full professional in the counseling field (Rønnestad \& Skovholt, 2003).

Any internalized responses to both positive and negative feedback from instructors and supervisors can generate unanticipated anxiety as the student adjusts to the unknown realities of life as a counselor (Rønnestad \& Skovholt, 2003). These reactions are nearly impossible to simulate in the classroom setting of the earlier stages of their experience. During the classroom-bound years of development, learning is driven by the counseling model being displayed by the formative instructors from the field who shape the learner in their development of counseling skills. This extends to growth in other areas, including all knowledge and insight gained by the student that will serve them later in the applied segments of the developmental process. It is then up to the student to remember these lessons and use them at the moments when they are put to the test in the field, the earliest of which could occur during practicum but even as far in the process as the state internship occurring in pursuit of licensure.

The internalization the student learner has brought with them into the program can just as easily be an asset or an additional adversary as well. The complexity of counselor education comes again from the nature of what is being learned. In prior phases of life, the person as a student may have learned that schooling is only useful in life in relation to the outcome, i.e., grades, and this shapes the view of the self(Bianchi \& Lancianese, 2005). In this ideology, people receiving good grades are good students and, hence, good people. By contrast, low grades resign the person to accepting they may be a "below standard" person. This simplistic approach to learning is decidedly unhelpful in a counseling program, as the knowledge is more directly related to being capable of internally experiencing the role of counselor and presenting the external stimuli of being the counselor to another human being 
dependent on receiving professional assistance.

Pieracci (1990) explored the concept of the Hero's Journey in connection with the client experiencing the hero role. In this discussion, the client would have to wrestle with the importance of their own achievement versus the relationship being forged in therapy. The parallel to this discussion is the counselor too would need to prove capable of achieving grades that result in becoming the counseling graduate, but the student must also forge a relationship with the material that allows for professional development towards becoming the counselor. In this application of the internalized world of the student, they must renounce the "outcome-only" message of the ordinary world, which would push them to seek grades only for purposes of earning a degree. Instead, they must aspire for something much higher: the counselor identity.

Throughout fictional uses of the mentor, the hero is safe from harm while traveling in the company of the guardian-mentor. While in the course-based phase of learning, the aspiring counselor as a student is shielded from many possible mistakes that would prove deleterious if made in the field with live clients. Ethics and multiculturalism, or other counseling courses that offer the average student topics to explore their ability to sidestep controversy, are key examples of challenges where the student must model the virtues of a mature counseling disposition (Brown, 2013). These courses are also great examples of the student being allowed to experience the internal challenge in a safe environment and fully benefitting from the opportunity to figure out what this new role really will mean in practice beyond concept. Eventually, the mentor is removed from the scenario, leaving only the student as the hero to realize it is their own choice to represent the hope they are seeking to bring to their world. The moral quality of these choices can no longer be curtailed by follow-up questions from faculty or the hypothetical nature of classroom learning. The student is now a representative of what a counselorin-training as the hero archetype will represent as they prepare for the road of trials into practicum.

\section{INITIATION OF THE COUNSELING ROLE}

Practicum as the Road of Trials

The transition from beginning to advanced student represents many changes for the new graduate student on the internal and external levels. It is expected that there would be initial excitement. However, the learning is difficulty, and the personal nature of becoming the counselor professional can often prove to be a complicated transition. This can depend on the openness of the learner and their flexibility to receive in an amicable fashion some of the more challenging concepts of the field related to value objectivity (Bugental \& Sapienza, 1992) and then be capable of forming successful relationships with clients who generate a sense of incongruence in the student-counselor (Lambert \& Barley, 2001; Leach, 2005). As this shift is experienced for much of the classroom learning of the graduate school experience, exposure to the new clinically-based situations can increase the intensity and desperation in the student due to a prolonged vulnerability not found in previous phases of the journey. The practicum experience is designed to translate theoretical knowledge into practice (Kurtyilmaz, 2015), and it grants the student the opportunity to experience the next phases of the journey.

To accomplish this, the advanced student applies their theoretical skills as a clinician to work face-to-face with live clients (Rønnestad \& Skovholt, 2003). Occurring at least two years after their initial decision to become more than an informal helper of others, the student will face challenges that are new to this stage of their growth. Paperwork as a clinician is often one of the most jarring transitions, as the goal of writing up to this point has been to support ideas with research using APA style. Now, the writing is related to effectively updating and contributing to the health records of clients (Piazza \& Baruth, 1990). Additional pressure could be felt if the student is completing their practicum requirements at a site where they operate as a part of a multidisciplinary team, as now other team members are relying on the quality of the practicum students notes, and they may not naturally be accustomed to creatively writing in this style.

The parallel in the monomyth to the trials of the practicum occur when the hero enters the inmost cave, which is described by Campbell (1949) as a place where the trials will target their insecurities on an emotional or psychological level. This can occur in many ways. The student is now spending

GRAND CANYON UNIVERSITY 
full days in the active role of a counselor, which is a shift away from their role as a student. This role of a counselor encompasses large periods of time where they are performing the task, and it can feel like a daunting challenge if they are not receiving feedback that serves to maintain their energy towards the experience. The student may also receive a client from a group with which they are not comfortable but be unable to refer them. If the student is not prepared for such a circumstance, this can be trying and even result in an unfortunate professional circumstance for them, the client, and the agency tasked with training the student. If this occurs, the student could have some internal struggles to overcome, similar to the hero being exposed to the lures of their shadow self (Jones, 2014). If the student fails to overcome this trial, they could face a prolonged period of time where they resent entire types of clients and operate in secret to stay under the radar of the supervisors in charge of gatekeeping, thus preventing them the opportunity to address these interpersonal blinds spots and affecting their professional development.

Another difficulty could be the student struggling with restoring their own life balance in the wake of a full day of clinically interacting with the most devastating problems imaginable. Counselors face the most devastating traumas the human condition can offer, often without prior warning. It is important that each member of the field develop effective strategies of self-care (MacKay, 2017), unique to their own person, and use them for processing these moments of pain in an effort to release them from their own psyche. Finally, the student could face a crisis of concept, realizing the simple solutions they were prepared to deliver mechanically for certain problems do not work in the nuanced scenarios of helping real people. Manuals are a great safety net for the novice counselor (Rønnestad \& Skovholt, 2003), but many issues require the creative capacity to tailor treatment interventions to the client in an individualized fashion (Fuertes \& Nutt Williams, 2017), which can feel risky to a new clinician who may lack the confidence to easily diverge from the script of the established protocol.

It is common for the student-hero to feel overwhelmed and even fail at some facets of the trial (McBride Steinberg, 2014) as they scramble to learn what is necessary to survive the seemingly endless tests assailing them. As a counseling student, they will continue to receive feedback from faculty involved in oversight, as well as from the supervisor of the practicum site, with the intention of seeing the counselor rise to the challenge and deliver effective help to the clients they are assisting during this training exercise. Through the brief moments of triumph, the student will hopefully take notice of the promise they show to one day reach the counselor ideal (Rønnestad \& Skovholt, 2003), even as the intensity of the practicum experience ceases to let up going into the final contact hours needed to fulfill the academic requirements of the advanced student.

\section{Meeting with the Goddess (Through Supervision)}

Since the moment the practicum students decided to apply and enroll in their first counseling courses, they have been aspiring to be a model of hope and efficiency for themselves and for future clients. They perceived counseling as the tool to overcome the unfortunate conditions conferred on the ordinary world by the corruption within the World Navel. The students saw themselves as a form of this solution, assuming a time would come when the skills are mastered. The goddess parallel (Byrne, 2000) for counselor development comes in the form of the practicum/internship/clinical supervisor. This individual functions as a model of exemplary practice in the profession (Gockel \& Burton, 2014; Rapp, Moody, \& Stewart, 2018). They possess the skills the student seeks. Even more so, the supervisor, like the Goddess of myth, possesses skills beyond the infantile understanding of the counselor-hero. The counselor must complete good work in order to have the privilege of collaborating with the supervisor. The supervisor has among their key roles that of the gatekeeper, meaning that the right of the student to become a counselor is not a foregone conclusion. The enjoyable life, as perceived in the underdeveloped sight of the counseling student, hangs in the balance based on the ongoing transaction and favor earned during the supervisory guidance.

From when the student applies and moves into the late stages of practicum, the mentor and supervisor have been completing their required duties to the field, even as they lend support to the student counselor. Primary among these is the role 
of gatekeeper to the profession (Swank \& SmithAdcock, 2014). Included in the counselor identity are the mandatory directives to ensure professional conduct is maintained that supports client autonomy, nonmaleficence, beneficence of work, justice, fidelity, and veracity towards others (American Counseling Association, 2014). If a student shows signs they cannot uphold these values, it is the duty of the gatekeeper to provide an opportunity for remediation (Rapp et al., 2018). If these efforts prove unsuccessful, an unfortunate end to this professional journey is a potential consequence. In such a case, the hero has met the goddess before they were capable, and the goddess has not granted her favor. In stories of myth where this occurs, the hero receives a curse, often leading to an ironic death that connects symbolically with the rationale for why the hero could not earn the favor of the goddess (Campbell, 1949). For the purpose of this stage in the counseling journey, the student could not behave as if they were a counselor, so they do not become a counselor. Gatekeeping functions in the tales of myth similar to the field of counseling.

Having proper congruence between interpersonal traits and behaviors exhibited during practicum can improve the facilitation of a successful practicum process. Redekop and Wlazelek (2012) identified key dispositions for a counseling applicant to maintain that lead to becoming an optimal match for education in the field of counseling: perception of self, perception of others, perception of purpose, and frame of reference. An engaged learner would be flexible and easily facilitate the counseling experiences with others. They would contain naturally within themselves the propensity to see the best in others and perceive them as capable and worthy of trust. They would have a strong starting point or understanding of the purpose and role of the counselor, and hence they would be compatible with conversations requiring an open-mind to accept client perceptions that differ from the personal views they hold. Finally, such a person would be interested in others, and as such they would desire to help them express their thoughts and feelings in pursuit of the counseling goal.

The meeting with the goddess provides the opportunity to enhance each of these qualities, all of which are expected to have been potentially present since the initiation of training (Campbell, 1949). If the hero demonstrates the proper balance of gentle awareness, humility, knowledge of the work ahead, and understanding of the involved struggle, they can receive the gifts needed to continue on with the journey. The feedback and trust experienced by the student should challenge them to develop skills beyond where they were at the beginning of the process. Assuming the student has the self-efficacy to grow from this guidance (Morrison \& Lent, 2018), they will move forward throughout practicum and intern training to further extend their helping abilities to the benefit of their clients with newly formed knowledge and insight. After receiving such gifts from the goddess, which in counselor training is the guidance and added skill gained through supervisory feedback, the student would then be capable of moving forward towards the final evaluation, as illustrated by the atonement of the father (Jones, 2014) as the evaluating agent of the student's counseling competence.

\section{Reflection: Facing the Temptress and Ethical Integration}

As a counselor educator, I have observed among my students that a few transformations that are expected over the course of being in a counseling cohort may come easily for some but be a complicated ordeal for others. These difficulties are critical to the spiritual journey of the student in relation to this exposition on counseling development as the Hero's Journey, as they become a complete parallel for facing the temptress and overcoming the shadow self as a hero would on their own epic quest. For the hero, the temptress comes to them near the end of the journey, just before the marrying the woman, and hence the success of the quest and acquisition of mastery over life (Campbell, 1949). This would represent a full acceptance of the philosophy of our goddess, which is the clinical supervisor. If this occurs, the student subscribes to all ethical insights, theoretical strategies, and shared techniques from the supervision process, and then they only face the acquisition of experience en route to the completion of the program, internship, and then state licensure. The temptress comes to remind the hero that the barriers of such matrimony could restrict the freedom of the hero, and she attempts to convince the hero that there is a better path to achieving 
the goal with less sacrifice of personal autonomy. In this scenario, the student may flirt with the notion that some ethical concepts are merely recommended but not required, and that these guidelines would actually hurt the development of appropriate rapport with certain clients and prevent the student from achieving their potential in certain ways. As an educator, I of course know this is a lie originating from our baser instincts, but the student in those moments must do what they know is right, or unfortunately they will engage in behaviors unbefitting the profession.

For this phase of the journey, the hero must remind themselves to transcend the human instinct to succumb to temptation, and then the true goal will come back into focus. In terms of ethical decision making, the student must develop good clinical judgment while in training, but also benefit from firmly maintained common sense (Bleiberg \& Baron, 2004), a moral compass, and a philosophical connection with the code of ethics in counseling and knowing why these principles exist. As I just identified, not all of these factors are inherent qualities; some must be learned and others must be decided upon by the student as they experience the stages of their own counselor development.

As illustrated in the acculturation model of ethical identity (Figure 1), students with a high personal and professional ethical identification will likely feel integrated into the ethical thought processes we explore in our coursework (Handelsman, Gottlieb, \& Knapp, 2005). This is the ideal and poses the least risk to decision making when the student moves into their professional life because the ethics exist in concert with the counseling student as a person. For the student with lower personal ethics, they can still feel that their work life demands high ethical development, and the term for this student is assimilation. This student uses their professional life to build up their predilection to engage in ethical thought outside of work, and they can often avoid ethical missteps, although they focus on preventing this concern less than an integrated professional. Some people have high ethical integration in their personal life and do not focus as much on how this applies to professional issues. These individuals experience a separation and are at risk of unethical behavior since they focus less on identifying the professional necessities of this thought process. Finally, a person who spends little time either personally or professionally at understanding these concepts is at the greatest risk of falling to the wiles of the temptress. This person is identified as experiencing an ethical marginalization, and the goal for this person is to begin building the ethical decisionmaking process into their professional life and then hopefully into their personal life. Any gap in ethical consideration makes the effort of adhering to the professional ethics seem a taxation of energy as opposed to being the necessary manner of presenting ourselves to our clients as professionals in the field.

Figure 1. Acculturation model applied to ethical identity

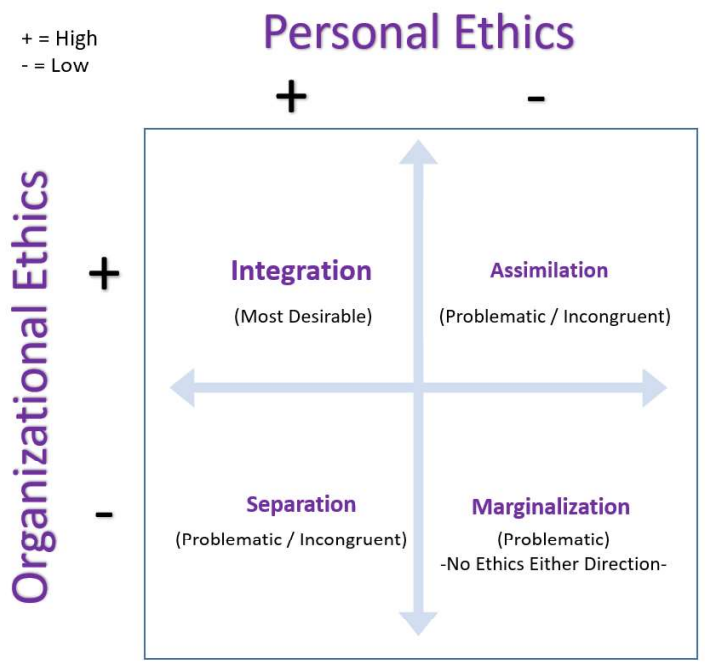

Adapted from Handelsman, Gottlieb, and Knapp (2005)

\section{Shadow}

One of the key archetypal concepts from the work of Carl Jung is that of the shadow (Murdock, 2017; Stein, 1998). If the student engages in dual relationships or other ethical mistakes, they could fall into a struggle with their shadow self in any attempt to correct course and regain the path of the ethical counseling professional (or student). The shadow self is appealing because it represents the desire for an easier path where the ideals of doing good are less of a burden. It promises the same reward with less obligation. It also takes advantage of our fears that we aren't good enough to excel on our own merits. Its power comes from internal tension, anxieties, and fear, and it uses these negative emotions to prioritize personal needs over 
the rules of society (Varghese \& Balasubramanian, 2017) and of the profession. The shadow can be different from person to person, but it connects naturally with our drive to achieve our desires. Our humanity is sacrificed if the shadow is given free reign and corrupts the very identity we swore to support in beginning the journey of the counselor. It is quite difficult to confront a student with their misdeeds, but it is necessary to do so or else the program we build loses credibility and the student's unfortunate behavior becomes what those clients believe counseling to be. The soul of our field is at stake with not only every decision we, who strive to be integrated in our ethics in the role of the noble hero, make, but also by the misguided students who stumble into mistakes and keep going unaware of how to correct course or accept remediation. We all must face our shadow and choose to be the counseling professional head on, or else we lie to ourselves and risk losing the identity we worked so hard to convince ourselves was a priority.

\section{Atonement with the Father: Evaluation of Progress}

Upon experiencing the successful meeting with the goddess, the hero of the monomyth moves on to reconcile all issues with the father. In the journey of the hero, the father is the omniscient being, capable of any deed, who possesses full knowledge of all the hero has experienced (Campbell, 1949). A merciful father allows for existence to occur, while a wrathful father could just as easily end all of life in both the ordinary and supernatural worlds. For the counseling metaphor to fit this phase of the journey, the university that grants the master's degree, and also the state that issues licensure, can be conceptualized as the father in the path of the developing counselor. By extension, the mentor or faculty advisor to the student, being in charge of ensuring the transcript meets graduation requirements, can be included in the concept of the father. Finally, the supervisor for internship hours can also be considered for this role. Any person in a position of verifying the completion of the required tasks contributes to the father of this symbolic journey.

This level of total evaluation is unique in the journey of the master's level counseling student, as it really does occur twice: once for the academic institution and then again for licensure. The father of this scenario delivers a tentative ruling, allowing the student to graduate and continue the journey to later stages. The true ruling comes when completing the licensure requirements, passing the final trial of examination, receiving the approval of the supervisor as the goddess, and becoming capable of heroic deeds/counseling without the supports of the supernatural aids or advanced mentors. This signals the beginning of the transition from novice counselor to experienced counseling professional (Rønnestad \& Skovholt, 2003).

Atonement with the father is the goal of these ordeals. This means that the hero is in possession of all virtues required for the larger task of acquiring the ultimate gift and restoring it to prominence in the ordinary world. This requires mastery of all that has been encountered, but it also means that all that has been experienced is now transformed into new knowledge (Holmes, 2007). The counseling student in this phase has the ability to use content from any course to reach a suitable interaction with the challenges of the counseling field. They also realize that this learning is a lifelong role and the challenges are never-ending. This is the steepest challenge our field has to offer, and it comes from humanism, in that we call it self-actualization. This concept of fulfilling all potential is the tallest of towers (Campbell, 1949), the Axis Mundi, which no counselor can truly ascend but we all strive for as we aim for exceptional distinction as helpers in our field. A counselor in tune with the field has achieved balance in their approach and mastery of their knowledge, and they align with the approach of good in their ethics and moral decision making. They have achieved all it takes to be effective helpers of humanity and only the fulfillment of goals remains before deciding how best to bring this gift to the masses of the ordinary world, the community they sought to help before enrolling in their graduate program.

\section{Reflection: Nadir \& Apotheosis}

It is quite common for students of mine to reach out and discuss their low points. This happens most often (it seems) at the deadlines for important assignments. Whenever this happens, I am brought back to the Hero's Journey and the concept of nadir. Nadir is, simply put, the lowest point of the journey (Dybicz, 2012). At this stage, the powers of evil have corralled the hero and are making the 
best attempt to prevent the hero from ascending to the highest summit. If the hero succeeds in that final task, they will claim the ultimate power and be capable of truly battling back the forces of evil. As an instructor, but also a former student, I remember vividly the feeling of knowing that I could complete an assignment if only I could get to my computer and write it. As a side note about me, I never once missed a deadline for an assignment at either the master's or doctorate levels of my training. It never occurred to me that I might not receive a zero for being a simple minute past midnight, so I never tested it and never realized my instructors appreciated this but were not nearly the rigid tyrants I feared they could be.

Many students do test this structure of their reality. They lend the power of nadir to their circumstance, and they let the pressure mount. It is also important to explain that in this metaphor nadir is not just any discomfort related to progress. It is the darkest discomfort when you are at the point where you either meet the deadline or you don't and you either fight or surrender. My memory of this feeling is coming up to the final day of true writing on my doctoral dissertation. I knew that if I could only stay up until three or four in the morning, and then, for the first time, the full five-chapter draft would exist. This is a daunting thought to realize and many people become afraid of that form of paramount progress. We procrastinate because we are afraid of moving forward in a true fashion (Holmes, 2007). Most students appear to feel this on every assignment, at least in small doses. The true nadir occurs after the role of student is over in the purgatory of internship where life still feels stunted by the directive of achieving experience. Nadir is experienced by this lifelong learner when they begin to feel like the ultimate fulfillment of their licensure is an endless cycle of demands with success permanently out of reach. All they have to do is decide to fight for progress one more time. The solution is found in another element of the journey: apotheosis.

Apotheosis is the final transformation of the hero at the highest level in the journey from ordinary to supernatural (Campbell, 1949). The hero becomes divine through an epiphany that leads to enlightenment (Jones, 2014). Evil no longer holds power over the hero, and the hero is fully capable of overcoming the obstacle of these opposing forces. This is the phase of triumph. For the counseling student, all challenges are complete, and the student is engaged in the final completion of tasks for the rite of passage to become a licensed counselor. All courses have been passed and the degree received years earlier. Supervision is completed and the hours experienced have tested the abilities of the counseling intern. The final challenge of the licensure exam has also been conquered by the counselor-in-training. All that is left is using the knowledge from these experiences to seize the ultimate gift and begin helping the world through a new identity. The student has experienced the full Hero's Journey and become a licensed professional counselor.

\section{The Ultimate Boon: Licensure \& Counselor Competence}

Once the professional counselor becomes licensed, they are then able to exit from the structures of supervision and frequent interaction with senior members of the field. In myth, this distinction is being delivered from the World Navel, which is the source of life, but through the very corruptions and imperfections of life the source also generated the discord that led the hero to seek change. In our analogy, the state board of health or other body governing the profession issues the honor of licensure as this ultimate gift. Entering the experienced professional phase (Rønnestad \& Skovholt, 2003), the hero's abilities to help will continue to refine themselves as new clinical experiences are acquired. Techniques will become more varied, common factors of change (such as therapeutic rapport) will be refined to higher levels, and greater trust in professional instincts will become hallmarks of continued clinical work. The ability to deliver exceptional clinical intervention to clients and help guide others to change is the ultimate boon in this conceptualization of the Hero's Journey. This journey is designed to explain how a hero seeks to combat the phenomena of tragedy and irony in the world of myth (Pieracci, 1990), while the experienced counselor similarly affects change in those experiencing depression, anxiety, trauma, and other psychological difficulties.

As the years continue, the maturity of the counselor-as-hero extends into the senior professional phase (Rønnestad \& Skovholt, 2003). 
While the counselor has achieved recognition in their community through years of service, they will also have achieved the supervision role and become gatekeepers for new heroes seeking to serve clients in the field. The leader role may feel like a good fit for some or may be intimidating to others. It is critical not to be overcome by the isolation of independence within the field, to continue to collaborate and engage in continuing education, and not succumb to apathy and boredom pertaining to the use of the gift of counseling (Glueck, 2015). Once a sought-after treasure, this ability could become the status quo, so it is important for the senior counselor to preserve their passion of the helping work in creative ways that reinvigorate the enthusiasm of their past self. Despite the ebb and flow of the endless use of the helping talent, the counselor-as-hero would still intellectually acknowledge the satisfaction from the work across all phases of the journey (Rønnestad \& Skovholt, 2003), even when the luster has faded from enduring the temporal experience.

\section{RETURN TO THE ORDINARY WORLD}

\section{Crossing of the Return Threshold}

After a lifetime of service to the goal of helping others suffer less in the ordinary world, the senior counselor experiences a return threshold in a few different ways. First, the return threshold is related to the ability to have a personal life free from the constraints of a graduate program or the intensity of meeting demanding professional requirements. Some heroes of myth do in fact avoid this return to normalcy (Campbell, 1949). If this occurs, those from the ordinary world may seek out the hero and convince them to return, while more comedic scenarios result in the gods frantically pursuing the hero to force the return to normal life. This shift in identity relates to the truth that we make sacrifices are made to pursue our goals as counselors. Family and friends have also experienced many things in life without their friend who sought to become the counseling professional. Completing the goals gives an opportunity to restore balance that was knowingly sacrificed in service of this professional goal. The return threshold is a metaphor for allowing ourselves to not be students anymore but to become lifelong learners who are allowed to be complete people in service to our identity, which is equal parts the counselor and ourselves. This is called, for the hero, becoming the "Master of Two Worlds."

\section{Reflection: The Master of Two Worlds}

I am going to share a difficult truth as a counselor educator who enjoys the daunting task of being a lifelong learner and teacher to future counselors and counseling educators. The bridge between the master of two worlds for the hero is sometimes a tough reality when understanding what it represents as a counselor educator. The world does not understand mental health. Our clients come from the ordinary world with ideas of how to help others and ideas of who can and cannot be "saved" through psychotherapy. Most of the time, these ingrained beliefs are well-intentioned. Often, with focused teaching they can be addressed and repurposed for effective use. However, not everyone is in our classroom, and they continue with these biases as if this is no problem at all. I have seen many relationships in my life shift because of this. This is not even due to the nefarious purposes of those family and friends seeking to do harm. It really just comes down to the world really not understanding mental health, cultural competence, active listening, self-care, ethics, and many of the other key components of the counselor identity that makes our profession a source of inspiration for those in the world who are hurting.

In myth, the hero often tries to flee the ordinary world or never returns to it. Frodo sails away to the Grey Havens with Gandalf and the other ringbearers (Tolkien, 1955). Luke Skywalker goes missing to grieve his failures on the unknown planet of Ach To (Abrams, 2017). These illustrate the plight of the hero after the initial journey. The lay person can be appreciative of the gift, but they do not understand the burden of carrying it or the implications of that responsibility on the psyche of the hero. I see these concerns in myself sometimes as I look at the movement of society, the phases of new legislation, the opinions of the general public, and the stigma related to mental health. Still, we keep helping. I have to believe that we can learn from these figures of reality and fiction alike and do better. After all, we have a gift for helping others, and they are surely better off with us in the battle to help, while keeping our presence focused on things we can change and leaving things we 
cannot change to others. Every day when we finish helping others, we can remember one last stage of the journey for the tested hero: the freedom to live for themselves.

\section{Freedom to Live}

This final stage of the monomyth before the circle is complete is the realization that the hero has the freedom to live for their self (Campbell, 1949). This occurs later in life and relates most directly to retirement from the helping profession or even the time to reflect positively on a life lived with integrity through healthy functioning of the ego (Goodcase \& Love, 2017) and the deeper meaning of a life lived helping others. The battle becomes less about good and evil in this phase for the hero, and for the counseling professional the journey is understood as the relationship between health and dysfunction. The goal was never to eradicate suffering at all but rather to show the world that we can find value in the appreciation of joy, meaning, and contentment wherever they are to be found. With any hope, counselors will feel effective as they experience this journey, and then they can find that place where they live a life that benefits from everything we come to learn about the human condition. If this occurs, we will have achieved true freedom to live a life well-lived. The journey is then complete.

\section{DISCUSSION \& CONCLUSION}

This discussion has sought to connect the Hero's Journey, as illustrated in the monomyth, archetypes, literature, film, and fiction, back to the realities of pursuing the fulfillment of the counselor identity. To this point, the principle of the Hero's Journey had been used in several instances of publication but always related to the growth of the client (Fortune et al., 2016; Pieracci, 1990) or the development of research/writing ideas (Holmes,

Figure 2. The Hero's Journey: As applied to counselor development

\section{The Hero's Journey}

\section{As Applied to Counselor Development}

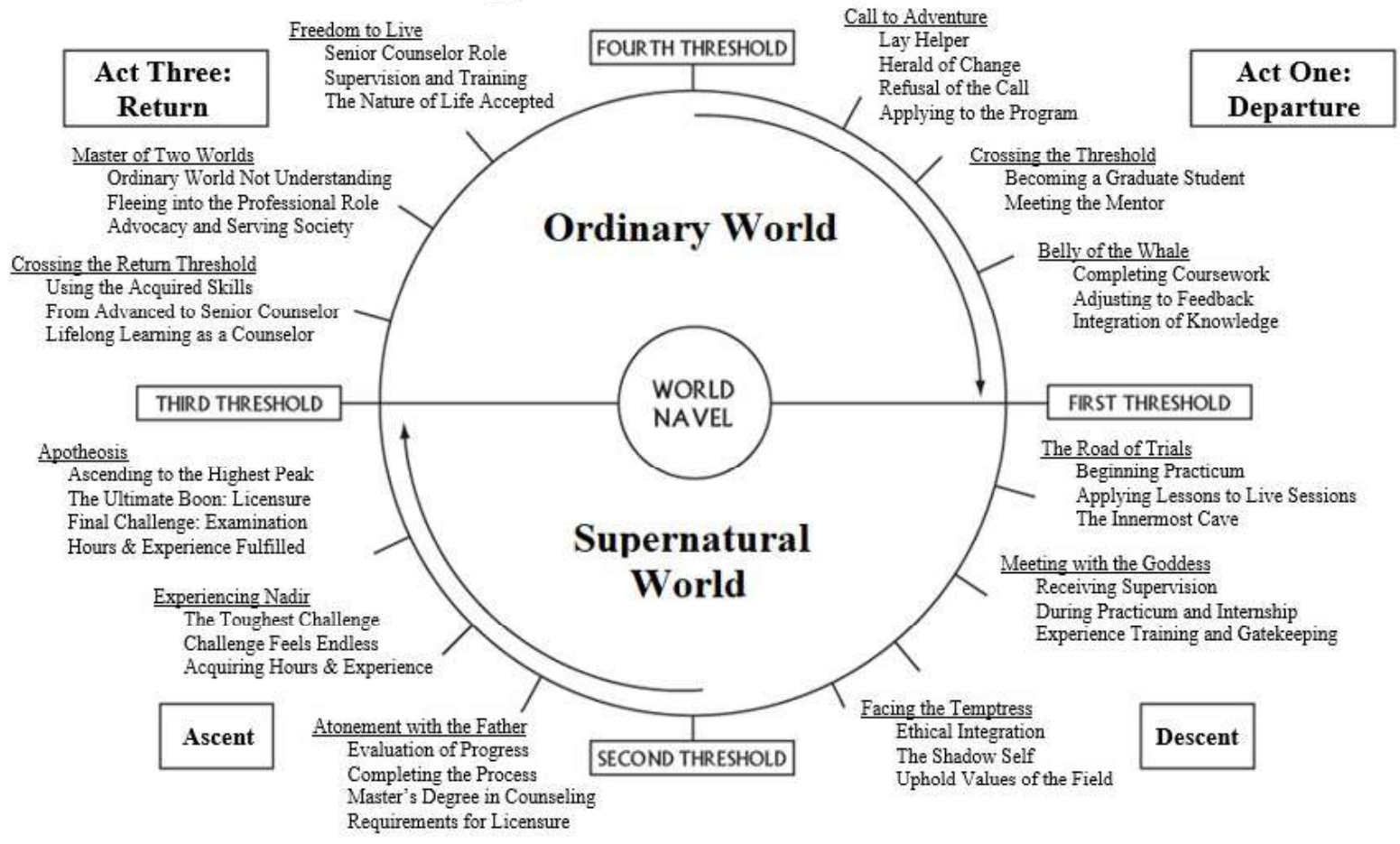

Act Two:

Initiation 
2007; McBride Steinberg, 2014). It is likely the experience of teaching counseling theories, skills, and various other courses can be enhanced by integrating the Hero's Journey as a way to illustrate the concepts of growth and philosophy inherent in many foundational concepts of our treatment approaches. With any hope, this concept can flourish among other educators in counseling to create a memorable hook for narrative development of what occurs symbolically across the growth of a counselor but also as a resource for helping incoming students to understand in a memorable way what kind of academic experience they are enrolling in, and what it will take on an existential level to achieve fulfillment in this profession.

The change within the person is the key to understanding counselor development as the Hero's Journey. Students learn through forming strong conceptual connections with material that grants the idea greater cognitive power (Rowley, Fook, \& Glazzard, 2018). By creating an opportunity to learn that utilizes easily recognizable characters and situations, the imperative of the idea is retained and with greater enthusiasm. This is the purpose of the monomyth throughout time (Campbell, 1949). The journey of the hero means more to us because it feels familiar, but it is also new with each retelling. This new vision of the journey's story is how a lay person becomes a master of the art that is counseling. From being a person who wants to help others in the world but lacks the skills and moving all the way through the challenges of a master's program, state internship, licensure exams, and then maneuvering the quests of practice in a complex and ever-evolving field, counseling is a source of hope similar to the promise of the empowered hero. At least, it can be if the instructor of the courses that capture the imagination of new minds entering the field believes in the metaphor.

The phases of the hero (departure, initiation, and return) give a full-spectrum understanding of counselor growth and related professional challenges. With any hope, this idea will continue to be expanded upon in future writings to establish the complete realization of the idea. As the monomyth is timeless, it is expected that we can retell this story again and again from different angles and emphasizing new challenges. The goal is to connect deeper with our conflicts to reach a sense of meaningful resolution, which comes through having the understanding and empowerment to interact with the struggle. It is my hope that students who learn from their mentors can grasp the importance of having counselors in the world, and this paper serves as a synthesis in sharing a creative way of illustrating why counseling truly is a gift that can affect change in our ordinary world.

Declaration of interest: The author reports no conflict of interest. The author alone is responsible for the content and writing of this article. 


\section{REFERENCES}

Abrams, J. J. (Producer), \& Johnson, R. (Director). (2017). The Last Jedi [Motion picture]. United States: Lucasfilm Ltd.

American Counseling Association. (2014). ACA Code of Ethics. Alexandria, VA: Author.

Berman, B. (Producer), \& Wachowski, L., \& Wachowski, L. (Directors). (1999). The Matrix [Motion picture]. United States: Warner Bros.

Bianchi, A. J., \& Lancianese, D. A. (2005). No child left behind?: Role/identity development of the "good student." International Journal of Educational Policy, Research, and Practice: Reconceptualizing Childhood Studies, 6(1), 3-29.

Bleiberg, J. R., \& Baron, J. (2004). Entanglement in dual relationships in a university counseling center. Journal of College Student Psychotherapy, 19(1), 21-34. doi:10.1300/ J035v19n01_05

Brown, M. (2013). A content analysis of problematic behavior in counselor education programs. Counselor Education and Supervision, 52(3), 179-192. doi:10.1002/j.15566978.2013.00036.x

Bugental, J. F. T., \& Sapienza, B. G. (1992). The three R's for humanistic psychology: Remembering, reconciling, reuniting. The Humanistic Psychologist, 20(2-3), 273-284. doi:10.1080/0 8873267.1992.9986795

Byrne, M. L. (2000). Heroes and Jungians. The San Francisco Jung Institute Library Journal, 18(3), 13-37. doi:10.1525/ jung.1.2000.18.3.13

Campbell, J. (1949). The hero with a thousand faces. Novato, CA: New World Library.

Cicco, G. (2012). Counseling instruction in the online classroom: A survey of student and faculty perceptions. Journal on School Educational Technology, 8(2), 1-10.

Dybicz, P. (2012). The hero(ine) on a journey: A postmodern conceptual framework for social work practice. Journal of Social Work Education, 48(2), 267-283. doi:10.5175/ JSWE.2012.201000057

Egan, G. (2014). The skilled helper (10th ed.). Belmont, CA: Brooks/ Cole, Cengage Learning.

Fortune, T., Ennals, P., Bhopti, A., Neilson, C., Darzins, S., \& Bruce, C. (2016). Bridging identity 'chasms': Occupational therapy academics' reflections on the journey towards scholarship. Teaching in Higher Education, 21(3), 313-325. doi:10.1080/13 562517.2016.1141289
Fuertes, J. N., \& Nutt Williams, E. (2017). Client-focused psychotherapy research. Journal of Counseling Psychology, 64(4), 369-375. doi:10.1037/cou0000214

Glueck, B. P. (2015). Roles, attitudes, and training needs of behavioral health clinicians in integrated primary care. Journal of Mental Health Counseling, 37(2), 175-188. doi:10.17744/ mehc.37.2.p84818638n07447r

Gockel, A., \& Burton, D. L. (2014). An evaluation of prepracticum helping skills training for graduate social work students. Journal of Social Work Education, 50(1), 101-119. doi:10.1080/ 10437797.2014.856234

Goodcase, E., \& Love, H. (2017). From despair to integrity: Using narrative therapy for older individuals in Erikson's last stage of identity development. Clinical Social Work Journal, 45(4), 354-363. doi:10.1007/s10615-016-0601-6

Handelsman, M. M., Gottlieb, M. C., \& Knapp, S. (2005). Training ethical psychologists: An acculturation model. Professional Psychology: Research and Practice, 36(1), 59-65. doi:10.1037/0735-7028.36.1.59

Holmes, T. (2007). The hero's journey: An inquiry-research model. Teacher Librarian, 34(5), 19-22.

Hurst, D., Cleveland-Innes, M., Hawranik, P., \& Gauvreau, S. (2013). Online graduate student identity and professional skills development. Canadian Journal of Higher Education, 43(3), $36-55$.

Jena, A. K. (2015). Students' perception is the instrument to predict the quality of teachers in higher education: A regression analysis. Journal on Educational Psychology, 9(1), 25-37.

Jones, K. (2014). An exploration of personality development through mythic narratives. Advanced Development Journal, 14,42 .

Kurtyilmaz, Y. (2015). Counselor trainees' views on their forthcoming experiences in practicum course. Eurasian Journal of Educational Research, (61), 155-180. doi:10.14689/ ejer.2015.61.9

Kurtz (Producer), \& Lucas, G. (Director). (1977). Star Wars Episode IV: A New Hope [Motion picture]. United States: 20th Century Fox.

Ladkin, D., Spitler, C., \& Craze, G. (2018). The journey of individuation: A Jungian alternative to the theory and practice of leading authentically. Leadership, 14(4), 415-434. doi:10.1177/1742715016681942

Lambert, M. J., \& Barley, D. E. (2001). Research summary on the therapeutic relationship and psychotherapy outcome. Psychotherapy: Theory, Research, Practice, Training, 38(4), 357-361. doi:10.1037/0033-3204.38.4.357 
Lawson, G. (2005). The hero's journey as a developmental metaphor in counseling. Journal of Humanistic Counseling, Education \& Development, 44(2), 134-144. doi:10.1002/ j.2164-490X.2005.tb00026.x

Leach, M. J. (2005). Rapport: A key to treatment success. Complementary Therapies in Clinical Practice, 11(4), 262-265. doi:10.1016/j.ctcp.2005.05.005

MacKay, L. M. (2017). Differentiation of self: Enhancing therapist resilience when working with relational trauma. Australian \& New Zealand Journal of Family Therapy, 38(4), 637-656. doi:10.1002/anzf.1276

McBride Steinberg, B. (2014). Embracing the journey. California English, 20(1), 16.

McCollum (Producer), \& Lucas, G. (Director). (1999). Star Wars Episode I: The Phantom Menace [Motion picture]. United States: Lucasfilm, Ltd.

Morrison, M. A., \& Lent, R. W. (2018). The working alliance, beliefs about the supervisor, and counseling self-efficacy: Applying the relational efficacy model to counselor supervision. Journal of Counseling, Psychology, 65(4), 512-522. doi:10.1037/cou0000267

Murdock, N. L. (2017). Theories of counseling and psychotherapy: A case approach (4th ed.). New York, NY: Pearson Education, Inc.

Piazza, N. J., \& Baruth, N. E. (1990). Client record guidelines. Journal of Counseling \& Development, 68(3), 313. doi:10.1002/j.1556-6676.1990.tb01380.x

Pieracci, M. (1990). The mythopoesis of psychotherapy. The Humanistic Psychologist, 18(2), 208-224. doi:10.1080/08873 267.1990.9976891

Rapp, M. C., Moody, S. J., \& Stewart, L. A. (2018). Becoming a gatekeeper: Recommendations for preparing doctoral students in counselor education. The Professional Counselor, 8(2), 190-199. doi:10.15241/mcr.8.2.190

Redekop, F., \& Wlazelek, B. (2012). Counselor dispositions: An added dimension for admissions decisions. Ideas and Research You Can Use: VISTAS 2012, 1(Article 17), 1-10. Retrieved from https://www.counseling.org/Resources/ Library/VISTAS/vistas12/Article_17.pdf

Rønnestad, M. H., \& Skovholt, T. M. (2003). The journey of the counselor and therapist: Research findings and perspectives on professional development. Journal of Career Development, 30(1), 5-44. doi:10.1177/089484530303000102
Rowley, C., Fook, J., \& Glazzard, J. (2018). Adopting a student-led pedagogic approach within higher education: The reflections of an early career academic. Reflective Practice: International and Multidisciplinary Perspectives, 19(1), 35-45. doi:10.1080/ 14623943.2017 .1351352

Rowling, J. K. (1997). Harry Potter and the philosopher's stone. London, UK: Bloomsbury.

Stein, M. (1998). Jung's map of the soul: An introduction. Chicago, IL: Open Court.

Swank, J. M., \& Smith-Adcock, S. (2014). Gatekeeping during admissions: A survey of counselor education programs. Counselor Education and Supervision, 53(1), 47-61. doi:10.1002/j.1556-6978.2014.00048.x

Tolkien, J. R. R. (1937). The hobbit: or there and back again. Boston, MA: Houghton Mifflin Company.

Tolkien, J. R. R. (1954). The fellowship of the ring. London, UK: Allen \& Unwin.

Tolkien, J. R. R. (1955). The return of the king. London, UK: Allen \& Unwin.

Trepal, H., Haberstroh, S., Duffey, T., \& Evans, M. (2007). Considerations and strategies for teaching online counseling skills: Establishing relationships in cyberspace. Counselor Education and Supervision, 46(4), 266-279. doi:10.1002/j.1556-6978.2007.tb00031.x

Varghese, S., \& Balasubramanian, A. (2017). Carl Jung's archetypes in Malayalam film: A case study on the film 'Urumi.' SHS Web of Conferences, 33(Article 18), International Conference on Communication and Media: An International Communication Association Regional Conference (i-COME'16). doi:10.1051/shsconf/20173300018 